\title{
Heuristics for Evaluating the Usability of Mobile Launchers for Elderly People
}

\author{
Muna S. Al-Razgan, Hend S. Al-Khalifa, and Mona D. Al-Shahrani \\ Information Technology Department, College of Computer and Information Sciences, \\ King Saud University, Riyadh, Saudi Arabia \\ \{malrazgan, hendk\} @ksu. edu.sa
}

\begin{abstract}
Touch based mobile phone launchers are programs used by elderly people to ease their use of mobile phones. Despite their varieties in the mobile phone market, little has been done to evaluate their applicability to the target users. In this paper we describe a systematic approach to convert design guidelines and recommendations for touch-based phones into heuristics targeting elderly people. Then an assessment of the heuristics is carried out by creating personas and conducting usability evaluation.
\end{abstract}

Keywords: Heuristics evaluation, usability, elderly people, touch-based mobile phones, personas.

\section{Introduction}

Mobile phone world is advancing with new technologies emerging each day. New, small and thin phones with new features and applications are being developed constantly. These phones are built with sophisticated features that hinder senior adults from using them. As the number of elderly people has increased [1], this fact signals the need for designing mobile phones targeting senior adults.

Previous studies have been conducted to evaluate the effectiveness of mobile phones in general e.g. [2], however mobile applications usability evaluation is still new area to research. A recent study in [3] presented a set of broad heuristics for mobile devices. Another more specific study evaluated existing iOS mobile applications for diabetes management and spotted drawbacks to avoid in designing such mobile applications [4]. The usability of mobile applications differs from regular software applications in issues related to context, connectivity, screen size and resolution, text and data entry methods. In [5] the authors proposed a general framework for conducting usability test for mobile applications.

From the research that we had reviewed and our own experience with elderly people, older adults are the people who are limited by some level of disability with an age of 50 and above [6]. These people require special attention in developing easy to use mobile phones. Therefore, there is a need to propose a corresponding set of heuristic that consider the specific needs of elderly people while interacting with touch-based mobile phones. 
In this paper, we introduce a new set of proposed heuristics for evaluating the usability of touch-based mobile phone launchers for elderly people. To our knowledge, no empirical research exists addressing the evaluation of touch based mobile launchers. Hence, our research will focus exclusively on the usability of elderly touch-based mobile launchers. These proposed heuristics were evaluated by usability evaluators to elicit feedback on the adequacy of our heuristics as will be illustrated in the paper.

\section{Methodology}

The process we used to develop usability heuristics for touch-based mobile phones for elderly followed these main steps:

- Convert previous guidelines into usability problems, and

- Group similar usability problems into categories.

Firstly, we converted guidelines that we had defined previously in our earlier publication [7], to usability problems, and combined similar ones under one category.

Secondly, we translated usability problems into heuristics that provide guidelines on how they can be avoided. The translated heuristics were also inspired by other heuristics that were adapted for older adults and the heuristics for Touch-based Mobile Devices (TMD) heuristics [5]. In addition, we have checked if any of the usability problems fit into the heuristics presented in [6][8] or do we need to develop a new heuristic.

After doing the previous systematic steps, we wrote the proposed heuristics as interrogative sentences, this is because interrogative sentences are more intuitive for answering and scoring compared to declarative sentences [6]. Then we elaborated our heuristics into list of questions.

Following the above process we came up with a list of newly proposed heuristics evaluation for touch-based mobile devices for elderly people, as illustrated in table 1. The heuristics are classified into three sections: (1) look and feel, (2) interaction, and (3) functionality.

Table 1. Touch-based Mobile Heuristics Evaluation for elderly people

\section{Look And Feel:}

\section{Make Elements on the page easy to read}

1.1. Is the font large enough for older adults?

1.2. Is there any option to enlarge the font size?

1.3. Are the text and background colors have good contrast?

1.4. Is it possible to customize colors?

1.5. Is the amount of text minimized; is the only necessary information presented?

1.6. Does color choices allow for easy readability? 
Table 1. (continued)

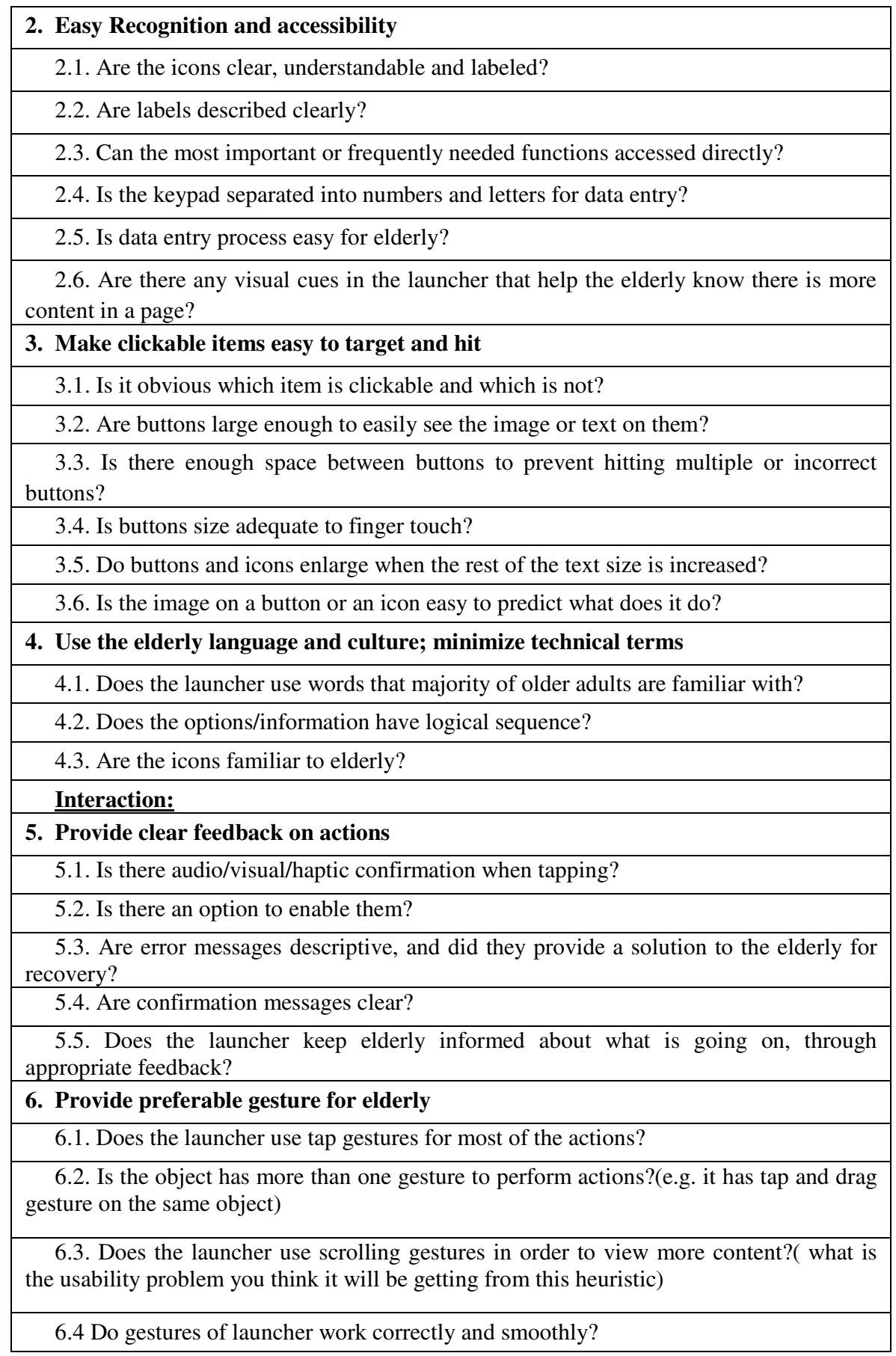


Table 1. (continued)

\begin{tabular}{|c|}
\hline 7. Provide elderly with information on launcher/elderly status \\
\hline 7.1. Does the elderly know where is he and what can he do next? \\
\hline $\begin{array}{l}\text { 7.2. Is the elderly aware when the launcher turns off or gets an error that causes it to } \\
\text { stop working? }\end{array}$ \\
\hline 8. Use conventional interaction items \\
\hline 8.1. Are items usage is the same from section to section within the launcher? \\
\hline 8.2. Does the launcher apply consistent format? \\
\hline 9. Ergonomics design \\
\hline 9.1. Are Items placed in recognizable positions? \\
\hline 9.2. Do the items in the elderly interface fit the natural posture of the hand and finger? \\
\hline Functionality: \\
\hline 10.Provide functions that reduce the elderly memory load \\
\hline $\begin{array}{l}\text { 10.1. Does the launcher support or provide shortcuts for direct access to the most } \\
\text { frequent functions or items? }\end{array}$ \\
\hline 10.2. Does the launcher provide supports to remember functions easily? \\
\hline $\begin{array}{l}\text { 10.3. Does the launcher group similar functions in one place? (example, \{call, contact } \\
\text { list, write text message in one group }\},\{\text { camera, pictures, videos in another group }\} \text { ) }\end{array}$ \\
\hline 10.4. Are the important functions always available (call, turn-off, etc)? \\
\hline 11.Elderly does not feel lost or stuck (Elderly control and freedom) \\
\hline 11.1. Does the main navigation menu exist consistently in all pages? \\
\hline $\begin{array}{l}\text { 11.2. Does clicking the back button always go back to the previous page that the } \\
\text { elderly comes from? }\end{array}$ \\
\hline $\begin{array}{l}\text { 11.3. Does the launcher provide emergency exits to leave unwanted state and is it } \\
\text { clearly pointed? }\end{array}$ \\
\hline 12.Prevent error from occurrence \\
\hline 12.1. Does the graphical interface design and the organization help prevent errors? \\
\hline 12.2. Is there confirmation message for critical actions such as deletion? \\
\hline 12.3. Are the important functions placed at top of the screen to avoid mistake touches? \\
\hline 13.Provide necessary information and settings \\
\hline $\begin{array}{l}\text { 13.1. Does the launcher show level of battery, time and date, signal of contact/Wi- } \\
\text { Fi/3G? }\end{array}$ \\
\hline $\begin{array}{l}\text { 13.2. Are the default settings of mobile phone available to the elderly in an easy way?( } \\
\text { e.g. change ringtone) }\end{array}$ \\
\hline
\end{tabular}




\section{Assessing Heuristic Performance}

We devised and conducted an experimental study aimed at assessing the appropriateness of the proposed heuristics.

\subsection{Participants and Materials}

The evaluation entailed four senior undergraduate students who have studied HCI course and conducted usability evaluation before.

Three launchers and three applications from Android market, as shown in table 2, were tested.

Table 2. List of Android Launchers and their description

\begin{tabular}{|l|l|}
\hline Launcher & Description \\
\hline Big Launcher & $\begin{array}{l}\text { A simple and easy-to-read interface designed for seniors and low } \\
\text { vision people }\end{array}$ \\
\hline Phonotto $^{2}$ & $\begin{array}{l}\text { A basic touch screen launcher for senior people includes the main } \\
\text { functions of regular phone of calling, address book, and send/receive } \\
\text { text messages. }\end{array}$ \\
\hline EasyPhone $^{3}$ & $\begin{array}{l}\text { An android application that provides extra large font for dial, call log, } \\
\text { contact, and SMS. The aim is for low vision people such as elderly. }\end{array}$ \\
\hline Liv $^{4}$ & $\begin{array}{l}\text { A large smart application operates with only four buttons navigational } \\
\text { buttons for simple use for elderly people }\end{array}$ \\
\hline Oldroid $^{5}$ & $\begin{array}{l}\text { A basic elderly application where the administrator can monitor the } \\
\text { setting of the phone through its website and will be synchronized } \\
\text { automatically. }\end{array}$ \\
\hline Georgie $^{6}$ & $\begin{array}{l}\text { An application has OCR function that display text in larger fonts and } \\
\text { offers an audio for listening. }\end{array}$ \\
\hline
\end{tabular}

We also developed two personas based on our knowledge in interacting with elderly people and from our previous experiment and research we reviewed [6]. These two personas represent different gender in addition to their ability to read and write.

Persona -1-, female, 61 years old, mother of six grandchildren. She lives with her son, and studies at the Literacy school. She can read and write but with mistakes. She

\footnotetext{
${ }^{1}$ http: / /www. biglauncher.com/

${ }^{2}$ https://play.google.com/store/apps / details?id=com.gammapps. SimplePhone\&hl=en

${ }^{3}$ https://play.google.com/store/apps/details?id=com.orange. labs . easyphone\&hl=en

${ }^{4}$ https://play.google.com/store/apps / details?id=com. livlivsolutions.skin\&feature=search_result

${ }^{5}$ www. oldroid.net

${ }^{6}$ http: / / www . engadget.com/2012/07/16/georgie-app-offersup-android-features-and-voice-guided-menus-visually-impaired/
} 
has a mobile phone with physical keyboard, but has not used a touch-based mobile phone before. She wear glasses when reading, she suffers from blood pressure, and hearing impairment. She has arthritis, so sometimes tapping on the screen is a problem.

Persona -2-, male, 76 years old, grandfather of seven children. He lives with his wife in the lower floor and his son with his children in the upper floor. He cannot read or even write. He has diabetes and suffers from memory impairment, and short temper. He uses a mobile phone with physical keyboard, and thinks that the new technology is difficult and he is not willing to learn it.

\subsection{Procedure}

To assess the performance of our proposed heuristics, the evaluation procedure followed the following protocols:

Orientation Session. This entailed welcoming the evaluators and explaining in detail the goals of the study and testing procedure. A training session was also conducted to explain the list of heuristics and how to assess them. The evaluators were asked to impersonate the two personas and write their observations [6]. Evaluation scripts were prepared in advanced and distrbuted among the evalutors.

Evaluation Session. The usability evaluators conducted the usability evaluation on each of the six Android launchers to identify usability problems, and prioritize them according to Nielson's five-point Severity Ranking scaled from 0-4, where 0-indicates no problem, 1- cosmetic problem, 2- Minor problem, and 4- catastrophic [9] . More explanation of the rating is presented in table 3. Also in order to avoid order effect, the sequence of launchers evaluation was counterbalanced for each evaluator.

Table 3. Severity Ranking Scale (SRS) borrowed from (adapted from [3])

\begin{tabular}{|l|l|}
\hline Rating & Description \\
\hline 0 & I don't agree that this is a usability problem at all \\
\hline 1 & $\begin{array}{l}\text { Cosmetic problem only. Need not be fixed unless extra time is available on } \\
\text { project }\end{array}$ \\
\hline 2 & Minor usability problem. Fixing this should be given low priority \\
\hline 3 & Major usability problem. Important to fix, so should be given high priority \\
\hline 4 & Usability catastrophes. Imperative to fix this before product can be released \\
\hline
\end{tabular}

Debriefing Session. After the usability evaluators have sent the evaluation results, they were asked to describe the experience of the process, i.e. strengths and limitations of using the heuristics to evaluate the launchers [10] [6]. Table 4, shows the asked questions. 
Table 4. Debriefing session questions

\begin{tabular}{|l|}
\hline What are the strength and limitation of these heuristics? \\
\hline Which heuristics are most useful? \\
\hline Which heuristics are difficult to understand? \\
\hline Does the heuristics cover all usability problems in these launchers? \\
\hline Are these heuristics easy to understand?(in general) \\
\hline
\end{tabular}

\section{Discussion and Results}

The data collected after conducting the usability evaluation were analyzed both quantitatively and qualitatively.

Quantitatively, after receiving the heuristics severity rating by each usability evaluator, we combined the results and came up with the following findings:

Most of the heuristics were rated as "no problem" by the evaluators. However, couple of them has varied severities. To further carry out the analysis, we had counted the severity rating by each evaluator for all of our proposed heuristics to measure how effective our proposed heuristics were.

Table 5. Parentage of Severity Ranking Scale (SRS)

\begin{tabular}{|l|c|}
\hline \multicolumn{1}{|c|}{ Severity ranking scale } & $\%$ \\
\hline No problem & $61 \%$ \\
\hline Cosmetic & $3 \%$ \\
\hline Minor & $9 \%$ \\
\hline Major & $12 \%$ \\
\hline Catastrophe & $16 \%$ \\
\hline
\end{tabular}

As depicted in Table 5, we noticed that $61 \%$ of evaluators had no problems when evaluating the six applications, which means that the available applications took into consideration the important criteria when designing elderly software. However, we noticed that the catastrophic rating (16\%) comes second in the severity list, although the evaluators were experts; this signals an alarm about the usability of the available applications for elderly people.

Table 6 shows the proposed heuristics and their corresponding usability problems found in the launchers. The look and feel category has the highest number of catastrophic issues which raise the importance of look and feel features for elderly, especially of their declining ability of low vision, and difficulties to recognize icons when their size is small. Functionality comes second in the number of usability problems. A launcher has to contain all the important functionality the elderly needs to make it easy to handle and attractive to use. The least number of problems was found in the interaction category, which indicates the impact of recent attention of the literature toward the increase elderly populations by designing launchers with good user experience that addresses elderly needs.

Furthermore to carry in-depth investigation of the problems found with the proposed heuristics, we discuss next the issues with highest rating (major and catastrophic). 
In heuristic 1.1 "is there any option to enlarge the font size?" and 1.4 "Is it possible to customize colors?" evaluators indicted that changing the text font or color using the installed launcher is not possible and required the changes to be done through the device setting. Examples of these launchers include "Olddriod, Liv+, Georgie, Phonotto (free version)". This issue will not be easy for the elderly to figure out, which is considered a major problem among the examined launchers.

In heuristic 2.1 "Are the icons clear, understandable and labeled?" evaluators pointed that some launchers placed text on top of icons. Designers have to take into consideration the specific needs of the elderly, if they cannot read; they need to present the launcher in two format (text, and image) icons, which can be set by the care giver based on the elderly ability. Also, for heuristic 2.6 "Are there any visual cues in the launcher that help the elderly know there is more content in a page?", evaluators, indicated that the user has to press + sign or tap arrows to know if there is more content in the page.

In heuristic 3.5 "Do buttons and icons enlarge when the rest of the text size is increased?" the experts stated that this option is not available in most of the launchers under investigations. Since our focus is on the heuristics not the specific launchers, we suggest the importance of enabling these features for elderly, especially with their declining ability of vision, difficulties to recognize icons when their size is small.

Table 6. Proposed heuristics and corresponding usability problems

\begin{tabular}{|c|c|}
\hline Description of heuristics & $\begin{array}{l}\text { Number of } \\
\text { usability problem }\end{array}$ \\
\hline \multicolumn{2}{|l|}{ Look And Feel: } \\
\hline \multicolumn{2}{|l|}{ 1. Make Elements on the page easy to read } \\
\hline 1.1. Is there any option to enlarge the font size? & 10 \\
\hline 1.4. Is it possible to customize colors? & 14 \\
\hline \multicolumn{2}{|l|}{ 2. Easy Recognition and accessibility } \\
\hline 2.1. Are the icons clear, understandable and labeled? & 8 \\
\hline $\begin{array}{l}\text { 2.6. Are there any visual cues in the launcher that help the } \\
\text { elderly know there is more content in a page? }\end{array}$ & 8 \\
\hline \multicolumn{2}{|l|}{ 3. $\quad$ Make clickable items easy to target and hit } \\
\hline $\begin{array}{l}\text { 3.5 Do buttons and icons enlarge when the rest of the text } \\
\text { size is increased? }\end{array}$ & 14 \\
\hline \multicolumn{2}{|l|}{ Interaction: } \\
\hline \multicolumn{2}{|l|}{ 5. $\quad$ Provide clear feedback on actions } \\
\hline 5.2 Is there an option to enable them? & 8 \\
\hline \multicolumn{2}{|l|}{ Functionality: } \\
\hline \multicolumn{2}{|l|}{ 12. Prevent error from occurrence } \\
\hline $\begin{array}{l}12.2 \text { Is there confirmation message for critical actions such } \\
\text { as deletion? }\end{array}$ & 11 \\
\hline \multicolumn{2}{|l|}{ Provide necessary information and settings } \\
\hline $\begin{array}{l}\text { 13.2 Are the default settings of mobile phone available to } \\
\text { the elderly in an easy way? (e.g. change ringtone) }\end{array}$ & 10 \\
\hline
\end{tabular}


In heuristic 5.2 "Is there an option to provide clear feedback on actions" the experts stated that this statement is not available in most of the examined launchers.

In heuristic (12.2 and 13.2) "Is there confirmation message for critical actions such as deletion?" and "Are the default settings of mobile phone available to the elderly in an easy way? (e.g. change ringtone)". These two heuristics are not available in the launchers that have been tested, such as when an elderly delete a message or a contact by mistake; there is no warning of his/her action. However, elderly people need it since they mostly have memory shortage or their hands are shaking, which might lead them to accidently pressing the delete button by mistake. The elderly has to be warned before completing any action by presenting a message along with sound.

The last heuristic was concerned about the default setting of the phone. Default phone settings are not available via the examined launchers which create a problem. As elderly will not be able to figure out how to change the ring tone from the phone settings, a launcher has to contain all the important functionality the elderly needs and make it easy to access.

Qualitatively, after finishing the evaluations we asked the usability evaluators for their input about the heuristics by answering table 4 questions. The evaluators stated that the heuristics covered the important needs for elderly people; which were the aim of our research. They also indicated that the heuristics were understandable, easy and simple especially for the "Look and feel \& interaction" category, as these show the importance of launchers appearance and the impact of the first impression to attract the elderly. However, one of the evaluators stated that some heuristics targeted specific functions without explaining the use of it to the elderly.

The evaluators also described some limitations of the heuristics. They mentioned that they could include some questions for the types of elderly who can read/write and those who cannot. Because some of the questions were not useful for the case of persona 2, and one evaluator said that "some questions like (is there any option to change font size, or customize colors) need to be in two parts" to help the evaluator to measure its availability and then its easiness for the elderly.

Other evaluators stated that the heuristics are missing the evaluation of "Responsive time" while using specific functions. As we know elderly usually require more time to do specific functions because of their limited abilities to learn new technology and their hesitation of making mistakes. For this reason we eliminated measuring the response time in our usability evaluation.

\section{Conclusion}

To recap, our study presented a proposed set of 13 heuristics which cover the usability of touch based mobile launchers designed for elderly people. These heuristics can be further used as guidelines when designing any launcher targeting elderly people.

Future direction of this research is to design a touch-based mobile phone launcher that covered the proposed heuristics. In addition, we will implement the launcher to address elderly Arab people cultural needs. We will also carry a user centered testing to evaluate our proposed launcher and adjust it according to the elderly needs. 
Acknowledgement. The authors would like to thank Elham Alsobky, Manahel Al Twaim, Moneerah Al-Mohsin, and Ibtihal Al-musallam for conducting the evaluation. This project is supported by grant no. D-C-12-117 from King Abdulaziz City for Science and Technology.

\section{References}

1. Plaza, I., Martín, L., Martin, S., Medrano, C.: Mobile applications in an aging society: Status and trends. J. Syst. Softw. 84(11), 1977-1988 (2011)

2. Connors, A., Sullivan, B.: W3C. Mobile Web Application Best Practices (2008), http: / / www.w3 .org/TR/mwabp/

3. Osais, Y.: Appropriating Usability Heuristics. In: Safari. Safari Books Online, pp. 1-14 (2011)

4. Martin, C., Flood, D., Sutton, D., Aldea, A., Harrison, R., Waite, M.: A Systematic Evaluation of Mobile Applications for Diabetes Management, pp. 466-469 (2011)

5. Zhang, D., Adipat, B.: Challenges, Methodologies, and Issues in the Usability Testing of Mobile Applications. Int. J. Hum. Comput. Interact. 18(3), 293-308 (2005)

6. Chisnell, D.E., Redish, J.C.G., Lee, A.M.Y.: New Heuristics for Understanding Older Adults as Web Users 53(1), 39-59 (2006)

7. Al-Razgan, M.S., Al-Khalifa, H.S., Al-Shahrani, M.D., AlAjmi, H.H.: Touch-Based mobile phone interface guidelines and design recommendations for elderly people: a survey of the literature. In: Huang, T., Zeng, Z., Li, C., Leung, C.S. (eds.) ICONIP 2012, Part IV. LNCS, vol. 7666, pp. 568-574. Springer, Heidelberg (2012)

8. Pinelle, D., Street, U., Hall, G.: Heuristic Evaluation for Games: Usability Principles for Video Game Design, pp. 1453-1462 (2008)

9. Nielsen, J.: Usability inspection methods. In: Conference Companion on Human Factors in Computing Systems, pp. 413-414. ACM (1994)

10. Masip, L., Granollers, T., Oliva, M.: A Heuristic Evaluation Experiment to Validate the New Set of Usability Heuristics. In: 2011 Eighth Int. Conf. Inf. Technol. New Gener, pp. 429-434 (April 2011) 